\title{
Investigación médica en Chile a la luz de la nueva legislación
}

\author{
Potential influence of recent modifications in Chilean \\ legislation for medical research
}

$\mathrm{E}$ n el contexto Latinoamericano Chile se ha ganado un prestigio que lo distingue cómo un país con instituciones confiables, bajo nivel de corrupción, estabilidad macroeconómica, con avances sociales, y niveles de educación y salud más que aceptables. Por cierto con amplios espacios de perfeccionamiento en todas las áreas, aún bastante lejos de países más desarrollados, y con brechas e inequidades aún irritantes; a pesar de lo cual, el reconocimiento internacional es bastante unánime. Este reconocimiento se extiende a las Instituciones de Educación Superior, específicamente a las Universidades de Investigación, y dentro de ellas las más destacadas, la Universidad de Chile, Pontificia Universidad Católica, Universidad de Concepción y la Universidad de Santiago de Chile, las cuales se ubican en el lugar 10, 14, 28 y 58 respectivamente en el ranking Scimago Latino Americano, basado en su productividad científica. Estas Instituciones y sus ecosistemas de investigación, instalan a Chile en el mapa de la "generación de conocimiento". También hay bastante consenso en que una sociedad que "genera" conocimiento se desarrolla más y mejor que aquella que sólo "importa" conocimiento. En el proceso de generación, sustentada fundamentalmente en la investigación de calidad, no sólo progresa quien lo desarrolla, no sólo se obtienen productos intelectuales, aplicaciones, y/o procesos específicos, sino que crecen y se desarrollan todos aquellos que directa e indirectamente participan del proceso, del ecosistema. Este es quizás el motivo central del por qué un país debe desarrollar investigación, en todos sus ámbitos, y en el máximo de las instituciones posibles, en la medida que tengan las capacidades para ello. En el mundo, y en Chile, las líneas de investigación que lideran por lejos la productividad son las relacionadas con ciencias de la vida, y dentro de ellas la investigación en Medicina. A manera de ejemplo, en el concurso Fondecyt Regular del año 2013, los 67 proyectos aprobados en el área de Medicina representan el 10,6\% del total aprobado, seguido de Química con 8,6\%. En conjunto con los proyectos de las áreas de las biologías (no todas relacionadas con bíomedicina), suman cerca del $25 \%$ del total de proyectos aprobados, y el $38 \%$ del total de recursos asignados.

En Medicina, el desarrollo de investigación requerida para generar nuevo conocimiento adquiere características que le son propias y que la hacen más compleja, más lenta, más incierta y riesgosa en diferentes aspectos, en comparación con investigación científica de "mesón", de carácter tecnológica, o relacionadas con el medioambiente, el universo, la economía, matemáticas, entre otras. La principal dificultad nace del hecho que requiere, para lograr sus objetivos, metodologías que incluyen intervenciones de carácter invasor en seres humanos, cuyo beneficio es su objetivo último. La posibilidad de que producto de su participación en investigación un sujeto pudiese sufrir un daño, de diferentes magnitudes y consecuencias, ha sido uno de los motivos centrales de la bioética. Se considera el primero de los cuatro principios bioéticos fundamentales: "primum non nocere" (propender a no producir daño), sumado a los principios de justicia, de beneficencia (propender a hacer el bien) y de autonomía.

En Chile, la investigación en seres humanos ha ido creciendo significativamente durante las últimas décadas, asociada a un crecimiento en el número de investigadores clínicos calificados, al incremento progresivo de recursos estatales para realizar investigación, especialmente a través de FONDECYT y más recientemente a través de los proyectos FONIS, y al incremento de estudios fármacoclínicos auspiciados por la industria farmacéutica. Este incremento ha tenido un impacto positivo al colocar a Chile en el "mapa" de la investigación biomédica mundial con investigaciones de calidad, incrementando la rigurosidad en el cuidado del paciente, especialmente para aquellos que participan de protocolos clínicos altamente exigentes, y en ocasiones aportando en infraestructura y equipamiento para los Centros participantes. Resultados de estudios en seres humanos realizados en el país han permitido la implementación de mejores diagnósticos y tratamientos, incremento en medidas de prevención de enfermedad incluyendo nuevas vacunas, así como la implementación de políticas públicas más robustas basadas en evidencia. El incremento de la investigación médica, por otro lado, se ha sucedido de una mayor visibilidad de esta actividad ante la opinión pública, y por ende del escrutinio público, con las fortalezas y debilidades del "juicio público". La principal debilidad a mi parecer, se relaciona con la falta de información/educación en el tema en nuestra población, una población frecuentemente dispuesta a identificar "culpables", y que se nutre de medios masivos presionado por los "ratings". En este ambiente, la notoriedad que adquieren "noticias negativas" sobre la 
investigación en seres humanos (influenciada por posturas editoriales unilaterales y con alta visibilidad como en la película el "Jardinero Fiel"), siembran mantos de dudas, en su gran medida injustificadas e injustas, sobre todo el ecosistema de la investigación médica. La principal fortaleza por otro lado, que nace de una preocupación tanto de individuos del mundo no médico, como de los propios investigadores, fue la de vislumbrar la urgente necesidad de darle un marco regulatorio a la investigación en seres humanos que diera garantías a todas las partes involucradas de que las investigaciones se realizarían dentro del marco ético internacionalmente aceptado, con información completa y garantías explícitas para los sujetos participantes, y claridad en las normativas para los investigadores y agencias/instituciones patrocinadoras.

El avance más significativo en esta materia en Chile fue la Norma Técnica $N^{\circ} 57$, desarrollada por un grupo de trabajo ad-hoc con significativa participación en su análisis y redacción inicial del Dr. Gustavo Kaltwasser, y quien suscribe, ambos miembros de Sociedad Chilena de Infectología. Este documento de "29 páginas y 5 anexos" como lo señala el Decreto Exento № 952 del 4 de junio, 2001 que le dio validez jurídica, se estructuró luego de un acabado análisis de normativas existentes en diferentes latitudes. Si bien el documento se centra en la "Regulación de la ejecución de ensayos clínicos que utilizan productos farmacéuticos en seres humanos", en él se abordan los principales temas relacionados con la investigación médica en general, incluyendo: principios éticos generales; requisitos que deben cumplir los estudios clínicos, investigadores, instituciones y patrocinantes ; el rol del Instituto de Salud Pública; estructura y funcionamiento de los Comités de Evaluación Ético-Científico; modelo de consentimiento informado; pautas para la acreditación de Comités Ético-Científicos; y las capacitaciones sugeridas para ir mejorando el sistema. Es una lectura recomendada para todos quienes participan de investigación en seres humanos en el país (Disponible a enero 2, 2013 en la página web http://medicina.uc.cl/ docman/344/doc-download). Al amparo de esta normativa se avanzó en la investigación médica que en Chile, al día de hoy, cumple estándares internacionales en forma adecuada. Una debilidad ha sido la falta de criterios objetivos en los procesos evaluativos que han derivado no infrecuentemente en proyectos aprobados por un comité de ética y rechazado por otro, dependiendo muchas veces de posiciones personales de integrantes de los diferentes comités. La necesidad de aprobación de múltiples comités para proyectos multicéntricos fue otra debilidad que entrabó el desarrollo de muchos proyectos de envergadura. La necesidad de profesionalización de los comités, tanto para incrementar la composición más experta y con mayor dedicación de tiempo de sus integrantes, así como un funcionamiento más expedito apoyado por secretarías con recursos adecuados se transformó al poco andar en una necesidad evidente.

La Ley 20.120, promulgada el año 2006 nace primordialmente para legislar sobre el tema de la clonación humana. Los primeros artículos se refieren a la prohibición de la práctica eugenésica (artículo 3), discriminación basada en el patrimonio genético (artículo 4), prohibición de la clonación de seres humanos (artículo 5). Se incluyen también un conjunto de artículos relacionados con el uso de cultivo de tejidos, terapia génica, el uso de información del genoma humano y de investigación científica en seres humanos en general. En forma explícita, se refiere en el artículo 10, a tres requisitos específicos para realizar investigación en seres humanos y en el artículo 11 se refiere al consentimiento informado. Ambos artículos no representan un cambio sustancial con lo previamente expresado en la Norma Técnica No 57 . En el artículo 16 crea la Comisión Nacional de Bioética. El 2010, cuatro años después, se aprueba el reglamento para esta ley que precisa algunos aspectos relacionados a los puntos anteriores. Los artículos 10 y 11 de este reglamento especifican el rol del Director del establecimiento donde se realiza la investigación como la persona exclusiva con facultad para autorizar su desarrollo y le obliga a fundar su decisión en un plazo de 20 días. Los artículos 11 a 15 se refieren al consentimiento informado y los artículos 16 a 18 al funcionamiento de los Comités Ético Científicos. Se establecen algunas nuevas precisiones aunque no se perciben cambios sustanciales en estos como en otros artículos que favorezcan o entraben el desarrollo de investigación en seres humanos en el país.

La Ley 20.584 promulgada en abril del año 2012 nace para legislar sobre los derechos y deberes de los pacientes, y al igual que la ley 20.120, incluye también en forma más bien tangencial, aspectos generales relacionados con la investigación en seres humanos. Es importante señalar que en esta ley, la investigación en seres humanos se aborda dentro de este marco de derechos y deberes de los pacientes y como tal debiera ser interpretada con cautela. En este contexto, y ante la posible interpretación literal de alguno de los artículos de esta ley, se ha generado una cierta preocupación sobre varios aspectos que interpretados en "forma literal", podrían afectar la investigación en seres humanos que se desarrolla en el país. Los artículos 12 y 13 se refieren al uso de la ficha clínica que prohibiría el uso de dicha ficha para fines de investigación al menos que se contara con la autorización mediante poder simple ante notario del titular de la ficha clínica, una acción claramente impracticable por razones obvias, especialmente para estudios de grandes casuísticas. Pero, la misma Ley en sus artículos 21 y 22 es explícita en señalar que toda persona "tendrá derecho a elegir su incorporación en cualquier tipo de investigación científica biomédica, en los términos de la ley $N^{\circ} 20.120 \ldots .$. . Una interpretación 
basado en el sentido común y análisis de conjunto de estos artículos permite visualizar que la protección de la privacidad del paciente, sentido de los artículos 12 y 13, quedarán resguardados al utilizarse la ficha clínica con fines de investigación, con el buen uso de los reglamentos asociados a la Norma Técnica № 57 y la ley 20.120. Por otro lado, el artículo 28 de la nueva Ley ha creado una seria preocupación pues señala en forma enfática que "Ninguna persona con discapacidad psíquica o intelectual que no pueda expresar su voluntad podrá participar en una investigación cientifica." Este artículo excluiría del proceso de investigación, y por ende de progreso médico, a personas en coma de cualquier tipo, pacientes con enfermedades psiquiátricas y degenerativas por mencionar solo algunos grupos en que se requiere de investigación para mejorar el diagnóstico, tratamiento, y prevención de estas enfermedades. De hecho, algunos Comités de Ética han rechazado proyectos, aludiendo a este artículo. La Ley 20.120 resolvería sólo parcialmente esta falencia al señalar en su artículo 11 "Toda investigación científica realizada con seres humanos deberá contar con el consentimiento previo, expreso, libre, informado y por escrito de la persona o, en su defecto, con el de aquel que deba suplir su voluntad en conformidad con la ley....". No pareciera suficientemente fuerte y claro este enunciado cómo para contrarrestar la intensidad del enunciado de la nueva ley referido a los sujetos con discapacidad psíquica o mental. La regulación que nacerá de la nueva ley deberá explicitar las exigencias para realizar investigación en estos grupos altamente vulnerables, que debieran ser mayores en varios aspectos, pero que por ningún motivo deberán de quedar excluidos de esta importante herramienta de progreso. Si se estima necesario, este artículo debiera ser modificado con urgencia. Es de esperar que los legisladores comprendan los argumentos detrás de esta afirmación.

En resumen, creo justo señalar que en Chile se ha progresado substancialmente en el tema de la regulación de los estudios en seres humanos, gracias al impulso significativo, perfectible por cierto, dado por la Norma Técnica No 57 del año 2001. La población está protegida razonablemente y los investigadores tienen un marco aceptable para desarrollar proyectos que beneficien a la población. Hay aspectos por aclarar en la nueva ley que deben ser abordados con apertura y atendiendo al espíritu en que fueron formulados; hay barreras burocráticas a la investigación en seres humanos que deben ser superadas (la exigencia de aprobación de un solo comité de ética acreditado será un paso relevante). Es importante que la comunidad comprenda los beneficios de la investigación rigurosa y respetuosa, lo cual es tarea permanente de los investigadores. En lo personal, tengo confianza en que el país tiene la madurez suficiente para aclarar los pocos puntos que han generado incertidumbre, especialmente el relacionado con la errónea exclusión del proceso de investigación clínica a personas con discapacidades psíquicas o intelectuales, y seguir avanzando en un camino de progreso que lo distingue como una comunidad que reflexiona con altura de miras y que por ende se acerca a paso firme hacia el desarrollo.

\section{Miguel O'Ryan \\ Universidad de Chile. Profesor Titular y Ex Vice-rector de Investigación y Desarrollo Sillón $N^{\circ} 17$ Academia de Medicina, Instituto de Chile. moryan@med.uchile.cl}

\section{Referencias bibliográficas}

1.- Grupos de Trabajo, Ministerio de Salud Ad-Hoc. Regulación de la ejecución de ensayos clínicos que utilizan productos farmacéuticos en seres humanos". Norma Técnica $\mathrm{N}^{\circ} 57$. Departamento de Programa de las Personas con la colaboración de Programa Regional de Bioética para América Latina y el Caribe, OPS/OMS

2.- Gobierno de Chile. Decreto Exento No 952 “Apruébese Norma Técnica para la regulación de ensayos clínicos que utilizan productos farmacéuticos en seres humanos" Junio 4, 2001.

3.- Gobierno de Chile. Ley No 20.120 Sobre la investigación científica en el ser humano, su genoma, y prohíbase la clonación humana. Septiembre 7, 2006.

4.- Subsecretaría de Salud Pública, Ministerio de Salud. Aprueba Reglamento de la Ley No 20.120 sobre la Investigación científica en el ser humano, su genoma, y prohíbe la clonación humana. Reglamento $\mathrm{N}^{\circ} 114$, publicado en el diario oficial Noviembre 19, 2011.

5.- Gobierno de Chile. Ley No 20.584 Regula los derechos y deberes que tienen las personas en relación con acciones vinculadas a su atención en salud. Abril 13, 2012. 